\title{
ir
}

\section{CALDERÓN EN EL LABERINTO TEXTUAL: INTENTIOY DISPOSITIO EN LAS VARIANTES DE LA TRADICIÓN}

\author{
Laurette Godinas \\ El Colegio de México \\ [Anuario calderoniano (ISSN: 1888-8046), 1, 2008, pp. 151-164]
}

A partir de mediados del siglo XVI, el teatro aurisecular es - por lo menos de lo que se puede documentar acerca de las representaciones y su contexto- un fenómeno cuya difusión tiene un carácter predominantemente oral. Cabe recordar que, si bien el número de lectores no deja, por las razones ya aludidas por Chartier - la multiplicación de los ejemplares gracias a la imprenta, con la correlativa baja de los costos de los materiales escritos, la ampliación de la planta de calígrafos, copistas desfuncionalizados que ofrecen sus servicios como maestros de escritura, la creciente actividad mercantil y la necesidad que conlleva de dejar por escrito los rastros de las transacciones, por citar sólo algunas- de aumentar, el público que asiste a las obras de teatro no es, en su gran mayoría, un público letrado. Por otra parte, tampoco podemos olvidar los avances logrados por muchos estudios gracias a los cuales se ha sensibilizado al lector contemporáneo de obras dramáticas acerca de las dos caras del hecho teatral, conforma- 
do por la mezcla indivisible de un texto dramático y del texto espectacular que le da vida, y de la comedia popular como un espectáculo global $^{1}$; no en balde afirmó Ignacio Arellano en su Historia del teatro español del siglo XVII que "las piezas dramáticas del Siglo de Oro se escribían, primordialmente, para ser representadas» y que «su consumo pertenece al territorio del espectáculo, y sólo secundariamente a la literatura» ${ }^{2}$.

Estas aportaciones de la semiótica teatral y de los enfoques socioculturales $^{3}$ — vinculadas principalmente con la difusión del teatro en su faceta espectacular - no deben, sin embargo, hacernos olvidar la importancia de la circulación de estas manifestaciones por la vía de la escritura. Al respecto, son sin duda los enormes avances en disciplinas como la bibliografia material, de origen anglosajón ${ }^{4}$ o la ecdótica los que nos ayudan a tener hoy una visión mucho más precisa acerca de este fenómeno cultural, cuyo entendimiento se vio durante mucho tiempo nublado por problemas de acercamiento filológico a la materia textual. No en balde cuando, a principios de los años setenta, Cruickshank y Wilson emprendieron la ingente tarea de organizar las labores de edición crítica de las comedias de Calderón de la Barca el primero afirmó de forma categórica que

For almost exactly three centurias Calderón's readers have been deceived by faked or forged editions of his work. In recent times, the deceptions and confusions have even involved non-existent editions, and the victims have included scholars, bibliographers and textual critics ${ }^{5}$.

${ }^{1}$ Pensemos en elementos contextuales que se pueden rastrear desde el texto bajo la forma de didascalias explícitas o implícitas como la creación de espacios teatrales, el uso de luces, las entradas y salidas de los actores, los elementos de vestuarios, es decir, todo lo relacionado con la representación. Sobre los problemas específicos de la edición de textos dramáticos, ver Reichenberger, 1991, pp. 417-419.

${ }^{2}$ Arellano, 1995, p. 61.

${ }^{3}$ Incluso teniendo en cuenta la visión sin duda un poco estrecha que dan Maravall, 1972, pp. 21-22 y algunos de sus alumnos (como Díez Borque, 1976) del público teatral como, en palabras de Catherine Connor, 2000, p. 7, «un público de masas, pasivo, manipulado, que percibe y responde unívocamente (si resulta capaz de responder de cualquier manera)".

${ }^{4}$ Ya llama la atención sobre esta necesidad Iglesias Feijoo, 2005, p. 27.

5 Cruickshand, 1973, p. 1. 
La elección de Calderón de la Barca para el análisis que nos proponemos aquí de las diferencias de dispositio e intentio en ambas vertientes del doble circuito de conservación y difusión de los textos dramáticos no es ninguna casualidad, puesto que éste es, sin duda alguna, el autor de cuya obra se han conservado más versiones manuscritas, muchas veces autógrafas, y uno de los pocos que cuidó de forma personal — directamente o con la ayuda de su hermano José6 — gran parte de las ediciones impresas de sus propias obras?

El estudio de la materia textual de las comedias que pasaron por la imprenta nos sitúa, pues, frente a un problema importante: si además se conservan manuscritos se observa, la mayor parte de las veces, numerosas variantes entre ambos estados de conservación que permiten hablar de dos fenómenos distintos, aunque estrechamente vinculados. Al primero, en cuya determinación entran factores que van más allá de características meramente estilísticas y formales, podemos calificarlo de intentio; al segundo, de índole formal, le queda el nombre, que tomo prestado de la metodología ecdótica, de dispositio.

\section{«INTENTIO»}

Parece tautológico afirmar que toda elección en relación con los canales de transmisión por los cuales pasará una obra determinada refleja la intención de quien lo pone a circular. Cabe destacar, sin embargo, que a partir de la implementación del nuevo invento que fue la imprenta rápidamente se pusieron en marcha mecanismos de control que restringieron el acceso a la misma para obras que no cumplieran con algunas características teleológicas imprescindibles, como su adscripción a cierto respeto hacia las buenas costumbres, única llave para pasar el escollo de la censura, y, claro está, la garantía, o por

${ }^{6}$ La Primera parte de 1636 fue «nominally edited by Calderón's younger brother, José, who may have been given prepared texts by his brother; or don Pedro may even have used his brother's name for the sake of appearances and done the work himself», Cruickshand, 1973, p. 2.

7 Son doce las Partes que aparecen en vida de Calderón: tres ediciones de la Parte primera y de la Segunda parte; y dos ediciones de las Tercera, Cuarta y Quinta partes, aunque la fecha real de edición de siete de estos volúmenes sitúa la época de auge de la circulación impresa de las obras de Calderón entre 1670 y 1677, en vez de 1640. 
lo menos la fe en ella que pudiese tener el arriesgado impresor, de su éxito comercial. La edición de los textos dramáticos cumplía con creces con esta última condición, como lo demuestran las sucesivas publicaciones de Partes de autores, de Partes de diferentes autores, de Comedias escogidas y el sinfin de sueltas que circularon por las manos de los autores y lectores de comedias en los siglos XVII y XVIII. Como bien lo apunta Ignacio Arellano en el apartado dedicado a la transmisión textual de las obras de Calderón de su estudio sobre Calderón y su escuela dramática, el éxito que conocieron las obras de Calderón provocó además la aparición de ediciones piratas o que provenían de modelos defectuosos ${ }^{8}$, para cuyo estudio el Manual bibliográfico calderoniano sigue siendo una herramienta fundamental ${ }^{9}$.

Un trabajo de revisión exhaustiva - imposible aquí, por evidentes limitaciones de espacio - no sólo de las obras de Calderón sino de todas las obras dramáticas que se conservan tanto en versiones manuscritas como impresas nos permitiría sin duda el establecimiento de una tipología de los cambios de intentiones entre ambas modalidades de difusión, lo cual a su vez permitiría explicar mejor las variaciones que se presentan entre el manuscrito y las versiones impresas (tomando en cuenta el abanico de posibles relaciones que se abren entre los distintos testimonios), o, a veces, en los distintos manuscritos entre sí y, aunque con menor frecuencia, entre las distintas versiones impresas (el caso más famoso sería, sin duda, el de La vida es sueño $0^{10}$ ).

Antes de proceder a la ejemplificación de lo anteriormente anunciado con casos que parecen marcar los dos extremos de la tipología propuesta, es decir un cambio marcado en la intentio frente a cambios menores que sólo atañen algunos detalles escénicos, cabe destacar que uno de los elementos que es necesario tomar en cuenta en el rastreo de las variaciones y, claro está, en la jerarquización de los testimonios, el punto hacia el que tiende toda la revisión de la transmisión textual de cualquier obra, es la presencia o no de una voluntad del autor en el proceso, es decir, si se puede documentar o no la participación del dramaturgo en la transmisión hoy conservada de su obra, sea a través de un manuscrito autógrafo, sea porque se puede suponer, como es el

\footnotetext{
${ }^{8}$ Arellano, 2001, pp. 55-56.

${ }^{9}$ Reichenberger, 1979-2003.

${ }^{10}$ Ver al respecto Vega García-Luengos, Cruickshank y Ruano de la Haza, 2001.
} 
caso para Pedro Calderón de la Barca, que intervino por lo menos en parte del proceso de edición de sus obras, bajo el nombre de su hermano José o en colaboración con él. En efecto, y volveremos más adelante sobre ello, frente a una versión que carece de autoridad en el sentido más etimológico de la palabra, la que se puede relacionar directamente con el autor tiene, por lo menos a priori, más probabilidades de reflejar la voluntad de éste, por lo menos en algún momento de su carrera literaria (y de la transmisión del texto). La aparición regular de ediciones de los autos sacramentales, a partir de la seminal edición crítica de Ignacio Arellano y Ángel L. Cilveti en 1992 y de la creación de un espacio específicamente dedicado a ellas en Reichenberger y la Universidad de Navarra, ha venido ofreciendo una mirada interesante sobre la transmisión textual de dichas obras dramáticas ${ }^{11}$. Queda por esperar que se amplíe el catálogo de comedias editadas según los mismos criterios ecdóticamente rigurosos para que tengamos por fin una idea más clara de los problemas textuales de las comedias del prolífico dramaturgo que dominó la escena teatral del siglo XVII.

Si empezamos por arriba, es decir, por la mayor presencia de modificaciones voluntarias que parecen indicar, en este caso, cambios en el receptor de la obra en cuestión, tenemos como ejemplo una de las obras de Calderón que, por su alta carga política y filosófica, más ha llamado la atención de la crítica moderna: El príncipe constante y esclavo por su patria ${ }^{12}$. En esta obra, no tenemos un caso en el que los cambios entre el manuscrito y los impresos se deba a una voluntad autoral, puesto que la letra del ms. 15159 de la Biblioteca Nacional de Madrid en el que se conserva la obra no es de Calderón. Pero sí de un testimonio de recepción muy valioso, puesto que, como bien lo dice Alberto Porqueras Mayo en su artículo «En torno al manuscrito del siglo XVII de El príncipe constante», el manuscrito ha sido revisado «por un director de comedias, con observaciones para los actores que debían estudiar los papeles, todo ello pensado para una representación o serie de representaciones específicas» ${ }^{13}$. Los cambios, evidentes desde el título —en el que se «vende» la obra como La gran comedia del

11 Calderón de la Barca, El divino Jasón.

${ }^{12}$ Ver al respecto Gascón Vera, 1983; Lumsden-Kouvel, 1983.

13 Porqueras Mayo, 1983. 
Príncipe constante y esclavo por su patria donde la primera edición de la Primera parte dice sólo Comedia famosa de El príncipe constante- incluyen una simplificación de los personajes femeninos en el reparto, mediante la adición de "no habla» después de Rosa y la supresión de las «moras» ${ }^{14}$. Pero sin duda donde más influyen los cambios que introduce la versión manuscrita es en la parte final de la escena VI:

$\begin{array}{ll}\text { Mul. } & \text { Suelta que no será en vano (Quítale el retrato.) } \\ & \text { que saque yo de la mano } \\ \text { a quien me saca del pecho. } & \text { Pero la caja me llama. (Tocan otra vez.) } \\ \text { Fén. } & \text { Rompe el retrato. }\end{array}$

MuL.

Si haré;

o en el mar le arrojaré

porque se aplaque su llama.

(Vanse cada uno por su lado $y$ toquen a desembarcar, $y$ salen don Enrique y don Fernando y don Juan de Silva, Cutiño y soldados.)

En la versión impresa la redondilla ("pero la caja... porque se aplaque su llama») no está; y, al contrario, al hablar de la llegada de los demás personajes se menciona un gran ruido de desembarque y un clarín, elementos que no aparecen, de forma tan explícita por lo menos, en el manuscrito. La ruptura del retrato al que se hacía alusión unos versos antes es, sin duda, un indicador de cambio en la sensibilidad del público, puesto que se sugiere una pasión incestuosa entre el rey de Fez y Fénix, su hermana (y no su hija, como en las ediciones). Éste y otros cambios, como la acotación de "desnúdase» en la escena VII de la jornada II, cuando el infante don Fernando al negociar su rescate a cambio de Ceuta, exclama «Rey, yo soy / tu esclavo, dispón, ordena», que demuestra la necesidad de representación simbólica del despojamiento o los versos que se añaden al final de la jornada III para salvar el honor de Tarundante, mostrando que es capaz de per-

14 Porqueras Mayo, 1983, p. 237. 
der con magnanimidad ${ }^{15}$, hacen pensar a Porqueras Mayo que se debió de tratar de una compañía andariega "compuesta de actores muy jóvenes, lo cual [...] explicaría que el rey de Fez apareciese como hermano, y no padre, de Fénix» ${ }^{16}$, destacando su interés como un instrumento para «recrear mentalmente una vívida representación teatral ante una audiencia provinciana del siglo XVII» ${ }^{17}$ y proponiendo su inclusión en el proceso de edición crítica de la obra.

Un caso similar es el que encontramos en Fieras afemina amor. Igualmente es conservada en un manuscrito de la obra completa, el ms. 17031 de la Biblioteca Nacional de Madrid ${ }^{18}$, y en tres testimonios impresos (una suelta y dos ediciones de la Quinta parte, respectivamente de Madrid y Barcelona, del año 1677), de los cuales la suelta parece haber sido copiada de un autógrafo de Calderón. Así, en un fragmento de gran interés textual ubicado al principio de la primera jornada (vv. 123-124), el manuscrito ofrece la lección siguiente:

$\begin{array}{ll}\text { Fénix } & \text { ¡Ah de los signos! } \\ \text { Coro } 2^{\circ} & \text { ¿Qué mandas? } \\ \text { PAVÓN } & \text { ¡Ah de los meses! } \\ \text { CORO } 3^{\circ} & \text { ¿Qué intentas? }\end{array}$

La suelta, en cambio, dice:

$\begin{array}{ll}\text { FÉNIX } & \text { ¡Ah de los siglos! } \\ \text { CORO 2 } & \text { ¿Qué mandas? } \\ \text { PAB. } & \text { ¡Ah de los astros! } \\ \text { CORO } 3^{\circ} & \text { ¿Qué intentas? }\end{array}$

15 Faltan en las ediciones los vv. 2943-2953: «Ella se casa a disgusto, / bien lo mostró en el semblante / cuando yo la cautivé / Cut.- Por Dios, señor Tarudante, / que se ha quedado a la luna. / Tar.- Antes, gracias debo darle / a Alá por el desengaño. / Alf.- Contento a tu tierra parte. / Fen.- Esta es mi mano, Muley. / Mul.- Fin tuvieron mis pesares. / (Danse las manos.) / Tu esclavo y esposo soy».

16 Porqueras Mayo, 1983, p. 246.

17 Porqueras Mayo, 1983, p. 248.

18 Además de un manuscrito fragmentario, el ms. 15581 de la misma Biblioteca Nacional, que contiene sólo las primeras dos jornadas y el «Baile para la fiesta», preparado para una representación real de 1724; ver al respecto Wilson, 1984, p. 3. 
La lección «siglos» por «signos» podría parecer un simple error de cajista; el cambio de «meses» por «astros» revela, en cambio, una acción deliberada. En efecto, asistimos en el manuscrito a una inversión de las características simbólicas de ambas aves: el Fénix, inmortal, se relaciona mejor con los siglos que con los signos, los cuales, como los astros, parecen remitir a la forma de estrella de los ojos que el pavón ostenta en su cola. Sin embargo, la suelta no está datada y, a pesar de no contar con un autógrafo, la lección que rectifica la atribución de características podría representar una trivialización del quiasmo lógico, apuntando hacia una adaptación a un público menos culto.

Otro caso es el de La desdicha de la voz, comedia de Calderón que se publicó en la Séptima parte de comedias del célebre poeta español Don Pedro Calderón de la Barca..., compilación tardía que forma parte de la labor editorial de Vera Tassis y Villaroel y sólo tuvo una edición en el siglo XVII. En este caso, el manuscrito sí es de Calderón y los cambios que en él se rastrean a menudo pasan a formar parte de los impresos. Uno de los casos más evidentes es sin duda cuando, en el diálogo de Isabel con Luquete y Leonor, tacha una página entera, entre los cuales se encuentran versos que ya había colocado de forma muy similar en 433-445.

Ms. Res. 108, Biblioteca Nacional, Madrid (vv. 607-636) ${ }^{19}$

No te aflijas mi cuydado mas que pesar es placer que en la casa en que vivimos a dos hermanos servimos

Ysa. $\quad Y$ esa es satisfacion (Luq.) Sí que más grande que dejar pues que mayor que olbidar a Madrid por tu velleza yo telo quiero estimar

Ysa. Yo lo estimo que el dejar a Madrid es gran fineça que es un bonito lugar pero mi alma [TACH. viene] buelve alli

${ }^{19}$ En cursiva lo que no está en las ediciones impresas. Se conserva la grafía del original. 
Luq. Disimular nos conpete

Sale Leonor

Leo. Isabel con quien aquí

hablando estas (Ysa.) Con Luquete

Leo. $\quad$ Fuese ya mi padre (Ysa.) Si

Leo. $\quad$ Donde [TACH. a mi hermano] Luquete as dejado a mi hermano (Luq.) El se apeó

Junto a la calle del prado

$y$ con el caballo yo

a casa vine enviado

de mi señor (Leo.) Pues oy que

tal fiesta en Madrid se de

falta al acompañamiento

$y$ sin gala $y$ lucimiento

gusta de quedarse a pie

Luq. $\quad$ El se debe de entender

Sale don Diego

d. di. Leonor (Leo.) que hay trais que turbado me llegas don Diego a ver

d. di. no te [TACH. turbas] aflijas mi cuydado mas que pesar es placer Ya te he dicho algunas veces

$$
\text { vv. 433-440 }
$$

$\mathrm{Y}$ esta es satisfacion

(Luq.) Si

pues que mayor que olbidar

a Madrid por tu velleza

Ysa. ya te creo que el dejar

a Madrid es gran fineza

porque es bonito lugar

Y donde más cambios estilísticos se aprecian es en la jornada III, donde las correcciones de los tachados permiten precisar y afinar versos que se podían mejorar. Si exceptuamos las anotaciones de «no»y «sí» en el margen de los versos 1005 a 1020, que parecen indicacio- 
nes de los editores posteriores para marcar la canción por la que optaron en vez de la que compuso Calderón ${ }^{20}$.

\section{«Dispositio»}

Los problemas inherentes a la diversidad patente en la presentación externa de los textos están básicamente relacionados con las diferencias que caracterizan los canales de difusión. Como es bien sabido, cada manuscrito es un testimonio aislado de una obra particular en el que se cuelan numerosas huellas contextuales que dependen de los azares de la transmisión. La imprenta, en cambio, implica una reproducción cuantitativamente más importante de ejemplares que, si bien no podemos eludir el problema de las variantes de emisión sobre las que enfoques metodológicos nuevos como la Bibliografia tanto han insistido, y tampoco se puede pasar por alto los problemas de transmisión que representa el relativo éxito de obras dramáticas y su reproducción no siempre autorizada por sus respectivos autores (situación, cabe decirlo, que se debe extender a otras obras no dramáticas que gozaron de los favores del público como el Quijote, sin ir más lejos) tiende a revestir las distintas versiones conservadas de una relativa uniformidad. No es ajena a ésta, claro está, la presencia en el proceso de la imprenta artesanal de un personaje clave, el cajista, que imprime a los textos que le son confiados las normas propias que parecen, sin embargo, responder a un conjunto de reglas implícitas vigentes en el ámbito en el que se mueve, reglas que encontramos de forma explícita desde el siglo XVII en el tratado de Víctor de Paredes titulado Institución y origen del arte de la imprenta y reglas generales para los componedores.

Por ello no son de extrañar, si comparamos las mismas obras desde el punto de vista exclusivamente formal, las diferencias entre, por un lado, el impreso o los testimonios manuscritos, copiados a una sola

${ }^{20}$ Es, por lo menos, lo que afirma en su edición Ebersole,Valencia, Castalia, 1963. Reemplazan la edición de 1715 y una suelta los versos: "Pues apenas el abril / bordará su esfera verde, / cuando se verá ceñido / de rosas y de claveles / ufano, gozando contento y alegre; / matiz en las flores, cristal en las fuentes. / Por.-Ya no les pienso pedir / más lágrimas a mis ojos, / porque dicen que no pueden / llorar tanto y ver tan poco». 
columna y con el nombre de los personajes a los que pertenecen los distintos diálogos en una posición marginal, con excepción de los que inician en medio del renglón, mientras que los textos impresos optan por un instrumento a su alcance, el cambio de una humanística redonda a una itálica, para marcar los cambios de personajes y colocan los versos, salvo los de arte mayor, a dos columnas con el fin de ahorrar espacio y papel: en efecto, es importante recordar al respecto que la imprenta convirtió la cultura en un negocio que responde a las reglas del mercado. Otro de los puntos de divergencia, también relacionado con este mismo ámbito formal, tiene que ver con las características gráficas de los distintos testimonios de la transmisión. Al respecto, podemos afirmar que, salvo en el caso de manuscritos autógrafos, donde la regularidad es un poco (aunque no del todo, lo cual confirma la idea de la inexistencia, hasta bien entrado el siglo XVIII, de normas ortográficas rígidas y, sobre todo, usuales entre los que tenían acceso al mundo de la escritura) mayor, las copias manuscritas muestran una gran vacilación en el uso de algunos alógrafos, particularmente la $<_{\mathrm{s}}>$, la $<\mathrm{z}>$, la $<\mathrm{r}>$ y los distintos modos de representar la oclusiva bilabial sonora o su variante intervocálica, donde alternan sin aparente distribución fija los grafemas $<\mathrm{u}>,<\mathrm{v}>\mathrm{y}<\mathrm{b}>$. En el caso de los impresos, si bien la regularidad no es total, se percibe una coherencia en el uso, si no morfológico, por lo menos de entidades semánticas mayores como las palabras. Del mismo modo, y como se ha podido documentar en otros tipos de textos tanto en versos no dramáticos como en prosa de no ficción - como por ejemplo en la puesta por escrito de testimonios orales en procesos inquisitoriales ${ }^{21}$ - el uso de la puntuación de los manuscritos no parece responder a ninguna pauta fija: o brilla por su (casi completa) ausencia, tanto en el verso como en la prosa, o, sobre todo en textos versificados, su uso se reduce al <.> como separador de palabras o de unidades métricas mayores, como la cuarteta.

${ }^{21}$ Ver al respecto mi artículo Godinas, en prensa. 


\section{Conclusiones}

Dos son las preocupaciones principales de la crítica textual. En primer lugar está la transmisión textual, cuyo fin es el de establecer una jerarquía de los testimonios para la elección del texto base y de los procedimientos de rescate de la variación textual. Al respecto, pudimos ejemplificar con el caso de El príncipe constante cómo los dos editores más recientes (Fernando Cantalapiedra y Alfredo Rodríguez López-Vázquez, 1996, Cátedra) optaron por presentar el texto del manuscrito 15159 como texto crítico, ofreciendo en un aparato de variantes final las lecciones de la tradición impresa, decisión que, tomando en cuenta la carencia de autoridad y el carácter contextual del texto en él contenido, podría dar a un lector no familiarizado una idea falseada del texto compuesto por Calderón. La misma falta de autoridad tiene la suelta que elige Wilson como texto de base para su edición de Fieras afemina amor, pues si bien las lecciones propuestas parecen más lógicas, no dejan de presentar diferencias que pueden resumirse a la intentio del autor. Por otro lado, presentar el manuscrito de La desdicha de la voz corresponde a la exposición del taller del dramaturgo, elemento que, si bien no carece de valor, tampoco parece digno de figurar como el texto crítico final y merecería más bien un lugar de honor en el aparato de variantes. Por otro lado encontramos la reflexión acerca de la forma, para que las decisiones relativas a la constitutio textus y la subsecuente dispositio se tomen con base en una profunda reflexión acerca de la sistematicidad intrínseca de cada uno de los testimonios y las reglas de transposición que se logren desprender de una versión a otra, ofreciendo criterios que, sin sacrificar del todo la legibilidad y correcta interpretación, permita dar fe, por lo menos en un estudio introductorio, de las características propias de los distintos usos gráficos en los diferentes testimonios.

La mayor parte de los autores en los que trabajemos nos pondrá en una situación en la que tengamos que revisar una transmisión textual híbrida hecha de manuscritos e impresos.Y sólo podremos tomar las decisiones pertinentes para la recensio y la constitutio textus si no perdemos de vista las diferencias que ambas modalidades de circulación y conservación implican en la intentio y la dispositio. 


\section{Bibliografía}

Arellano, I., Historia del teatro español del siglo XVII, Madrid, Cátedra, 1995.

- Calderón y su escuela dramática, Madrid, Laberinto, 2001.

Calderón de la Barca, P., El divino Jasón, ed. I. Arellano y Á. L. Cilveti, Kassel / Pamplona, Reichenberger / Universidad de Navarra, 1992.

CONNOR, C., "Hacia una teoría sociocultural del espectador aurisecular», en El texto puesto en escena. Estudios sobre la comedia del Siglo de Oro en honor a Everett W. Hesse, ed. B. Mujica y A. K. Stoll, London, Tamesis, 2000, pp. 65-78.

Cruickshand, D. W., "The textual criticism of Calderón's comedias: a survey», en Calderón de la Barca, P., Comedias. A facsímile edition, London, Gregg-Tamesis, 1973, pp. 1-53.

Díez Borque, J. M., Sociología de la comedia española del siglo XVII, Madrid, Cátedra, 1976.

Gascón Vera, E., «La voluntad y el deseo en El príncipe constante», en Calderón. Actas del Congreso Internacional sobre Calderón y el Teatro Español del Siglo de Oro, ed. L. García Lorenzo, Madrid, CSIC, 1983, vol. 1, pp. 451459.

GODINAS, L., «La puntuación en textos festivos novohispanos: de la recensio a la constitutio textus», en Fiesta y celebración: espacio y discurso novohispanos, ed. M. Á. Méndez, México, El Colegio de México, en prensa.

Iglesias Fejoo, L., «En el texto de Calderón: teatro y crítica textual, a propósito de La vida es sueño", en Estudios de teatro español y novohispano, ed. M. Romanos, F. Calvo y X. González, Buenos Aires, Universidad de Buenos Aires, 2005, pp. 23-55.

Lumsden-Kouvel, A., "El príncipe constante: drama de la contrarreforma. La tragedia de un santo mártir», en Calderón. Actas del Congreso Internacional sobre Calderón y el Teatro Español del Siglo de Oro, ed. L. García Lorenzo, Madrid, CSIC, 1983, vol. 1, pp. 495-501.

Maravall, J. A., Teatro y literatura en la sociedad barroca, Madrid, Seminarios y Ediciones, 1972.

Paredes Alonso, V. De, Institución y origen del arte de la imprenta y reglas generales para los componedores (siglo XVII), ed. J. Moll, Madrid, Calambur, 2002.

Porqueras Mayo, A., "En torno al manuscrito del siglo XVII de El príncipe constante. Notas sobre representación dramática en la Edad de Oro», en Calderón. Actas del Congreso Internacional sobre Calderón y el Teatro Español del Siglo de Oro, ed. L. García Lorenzo, Madrid, CSIC, 1983, vol. 1, pp. 235-248.

Reichenberger, K., Manual bibliográfico calderoniano, Kassel, Thiele und Schwarz, 1979-2003. 
— «Ediciones críticas de textos dramáticos. Problemas antiguos y recientes», en Crítica textual y anotación filológica en obras del Siglo de Oro, ed. I. Arellano y J. Cañedo, Madrid, Castalia, 1991 pp. 417-430.

Vega García-Luengos, G., D. W. Cruickshank y J. Ruano del Haza (eds.), La segunda versión de "La vida es sueño», de Calderón, Liverpool, Liverpool University Press, 2001.

WiLson, E. M., «Introduction», en P. Calderón de la Barca, Fieras afemina amor, Kassel, Reichenberger, 1984. 